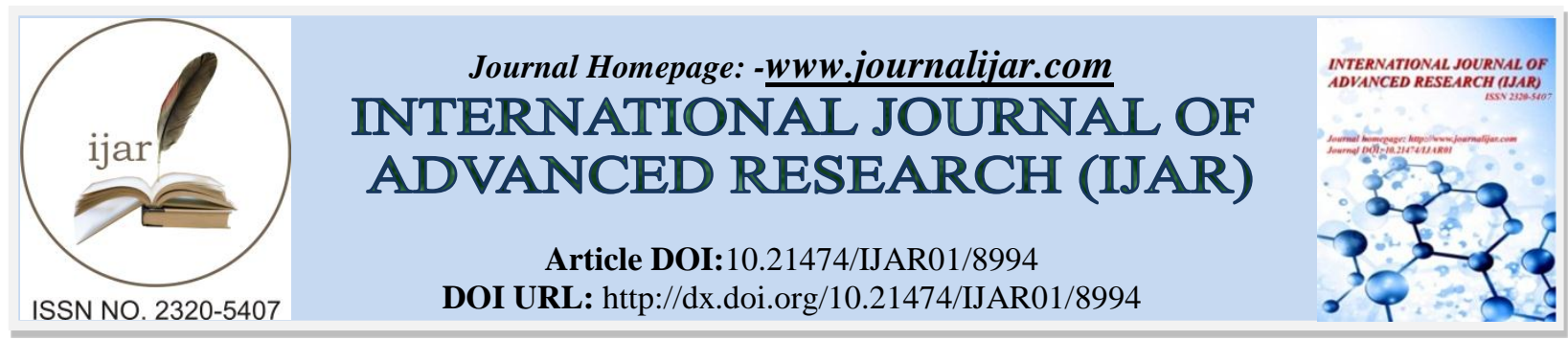

RESEARCH ARTICLE

\title{
SINGLE COMPLETE MAXILLARY DENTURE WITH METAL DENTURE BASE - A CASE REPORT.
}

Dr.Vrinda Gupta And Dr.Preeti Satheesh Kumar.

1. Post Graduate in Prosthodontics (RGUHS).

2. Professor,Dept of Prosthodontics, The Oxford Dental College and Research Centre,Bangalore.

\section{Manuscript Info}

Manuscript History

Received: 27 February 2019

Final Accepted: 29 March 2019

Published: April 2019

Key words:-

Single Complete Denture, Metal Denture

Base, Denture Base Material.

\begin{abstract}
Treatment involving the use of a single complete denture offers various challenges to the clinician and requires careful evaluation and planning. The conditions leading to the recommendation of such a treatment can be quite varied and often compromise the success unless the opposing arch is optimally treated. Although heat cure denture base resins are the most commonly used denture base material, they are commonly found to fracture when a single complete denture is opposed to the natural dentition. In such cases, the use of a metal denture base offers many advantages as an alternative treatment option. This case report describes step by step fabrication of a single complete denture with metal denture base.
\end{abstract}

Copy Right, IJAR, 2019,. All rights reserved.

\section{Introduction:-}

Single complete dentures may be opposed by: natural teeth, fixed restorations, a removable partial denture or an existing complete denture. (Zarb et al., 1990) The most common clinical situation involving a single complete denture is that of an upper complete denture and lower natural teeth. (Ellinger et al., 1971)Heat cured denture base resins are the most common material used for the fabrication of denture bases as they provide acceptable physical, biologic and aesthetic characteristics at moderate expense. However, denture base resins in single complete dentures have been frequently found to fracture under excess masticatory forces. (Mattie and Phoenix, 1996) According to Koper, occlusal problems and denture-base fractures seen in the single complete denture are the result of one or all of the following: (1) occlusal stress on the maxillary denture and the underlying edentulous tissue from teeth and musculature accustomed to opposing natural teeth, (2) the position of the mandibular teeth, which may not be properly aligned for the bilateral balance needed for stability, and (3) flexure of the denture base. (Koper, 1987) As an alternative treatment option, metal denture bases have proven to impart strength to the single complete dentures opposing the natural dentition and prevent them from fracturing. Metal based dentures offer many advantages. They are more retentive, have a reduced incidence of fracture, offer better thermal conductivity, act as a stable record base, cause fewer sore spots, better preserve the residual alveolar ridge, less porous, deform less during lateral mandibular function and provide more accuracy in tissue detailing. (Belfiglio, 1987) Thinner metallic denture bases also reduce interferences with phonation. They also do not show sorption related changes as seen in denture base resins. (Mattie and Phoenix, 1996) Also, as the use of metal bases reduces the amount of acrylic resin in the denture, processing changes can be reduced too. Metal bases for complete dentures are indicated when a high degree of processing change is expected such as with a deep palatal vault or when additional strength is needed. The use is also indicated in overdentures, because the stresses are concentrated over small parts of the dentures or shallow, flat palates, because these anatomic features allow for flexure that can result in fractures; and in patients with

Corresponding Author:-Dr.Vrinda Gupta.

Address:-Post Graduate in Prosthodontics (RGUHS). 
compromised neuromuscular coordination who may drop their dentures. The few disadvantages include increased cost, increased laboratory working time, difficult relining/rebasing and the possible allergy to metal. (Belfiglio, 1987) This case report describes step by step fabrication of a single complete denture with metal denture base.

\section{Diagnosis and Treatment Planning}

A 59-year-old male patient reported to the Department of Prosthodontics, The Oxford Dental College and Hospital, Bengaluru, India, with a chief complaint of missing teeth in upper arch and wanted them to be replaced by a prosthesis to restore esthetics and speech. A complete case history was recorded. Past dental history revealed that patient had an earlier history of two broken dentures. Also, a thorough intraoral examination was done. The maxillary arch was completely edentulous supported by a well formed ridge. Mandibular teeth were having good periodontal support without any associated mobility. Patient was also asked to get a full mouth radiograph (OPG) and undergo routine blood investigations in which no significant abnormality was detected.

A treatment plan was formulated and the patient was advised to opt for a single complete denture for maxillary edentulous arch with metal denture base. The patient was educated and motivated regarding the use of removable single complete dentures.

\section{Classification of single complete denture (Driscoll, 2004)}

1. Class 1 -Patients for whom minor, or no, tooth reduction is all that is needed to obtain balance.

2. Class 2 -Patients for whom minor additions to the height of the teeth are needed to obtainbalance.

3. Class 3 - Patients for whom both reductions and additions to teeth are required to obtainbalance.The treatment of these patients usually involves a change in vertical dimension of occlusion.

4. Class 4 - Patients who present with occlusal discrepancies that require addition to the width of the occlusing surface.

5. Class 5 - Patients who present with combination syndrome.

\section{Preprosthetic Phase}

The patient was categorized as Class 1 patient as minor, or no, tooth reduction was needed to obtain balance. Diagnostic casts were made and examined carefully to identify malposed or supraerupted teeth. (Fig 1 \& 2) Necessary corrections were made to improve the alignment of the opposing dentition.

\section{Procedure}

Primary impressions of the maxillary and mandibular arches were made. Maxillary arch impression was made with medium fusing impression compound (DPI, Mumbai) and mandibular arch impression was made with irreversible hydrocolloid impression material (Zhermak, Italy). The primary impressions were disinfected and poured in dental plaster and dental stone respectively. A temporary record base for the maxillary arch was made using autopolymerizing acrylic resin and occlusal rim was made using the modeling wax. After tentative jaw relation, diagnostic mounting was done to check the inter- arch distance.

A custom tray was fabricated on the primary cast after adaptation of a wax spacer. On the second visit, border molding was done using the custom tray and a wash impression was made using zinc oxide eugenol paste. The impression was disinfected and master cast was poured using the dental stone. (Fig $3 \& 4$ ) The master cast was then duplicated with agar-agar (reversible hydrocolloid)) to get a working cast. (Fig 5 \& 6) The pattern of the metal frame work was designed and adapted on the working cast of the maxillary edentulous arch. The pattern of the metal base was kept short of posterior palatal seal area to retain control over the adjustability of the posterior palatal seal. A lubricant was applied to the duplicated cast for easy removal of wax pattern. Sprues of $4 \mathrm{~mm}$ diameter and crucible former were attached to the wax pattern and the wax pattern was lifted from the cast with care to prevent any distortion. (Fig 7) The sprued wax pattern was then invested using the investment material (Bego). A cobalt-chrome alloy (Bego, Germany) was used as the material for denture base because of reasonable cost and good retentive properties. The metal framework was then transferred on to the master cast and checked for adaptation. A wax occlusal rim was fabricated on the metal denture base and maxillo-mandibular jaw relation record was made. (Fig 8) A face bow transfer was done and master casts were mounted on the articulator using the jaw relation record. The maxillary teeth were arranged according to the contour of the maxillary occlusion rim and aligned along the occlusal surface. A try in was done in the next appointment. The posterior palatal seal was carved out on the master cast to provide the essential border seal in the region. The maxillary metal denture base with the teeth arrangement was then invested and dewaxed using the regular procedure. The denture was packed using the heat cure denture material 
(Trevalon) and cured in the regular way. After bench cooling, the denture was removed and finished and polished. (Fig 9) Insertion was done and post insertion instructions were given to the patient. (Fig 10)

\section{Summary}

Metal bases for complete dentures have been used successfully and provide many advantages over the more commonly used acrylic resin. The few disadvantages are far outweighed by the many advantages. The possibility of allergy to the metal, although a valid concern, varies with the composition and electrochemical properties of the alloy and the susceptibility of the patient. With metal bases in dentures, the patient benefits by having a more comfortable, better fitting and stronger prosthesis. The dentist benefits by reducing post insertion visits and providing rehabilitation that will better satisfy the patient.

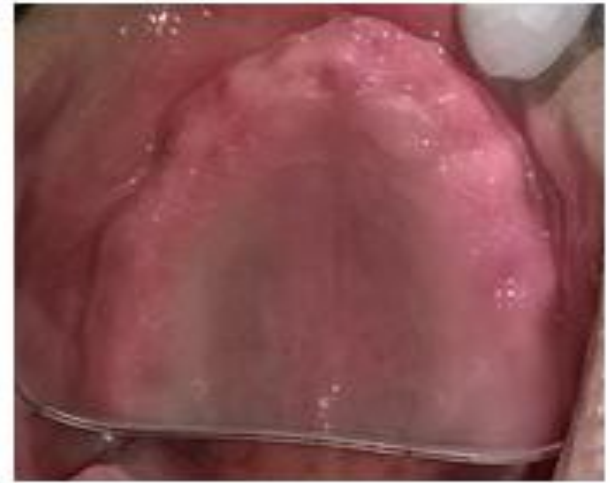

Fig 1 - Maxillary

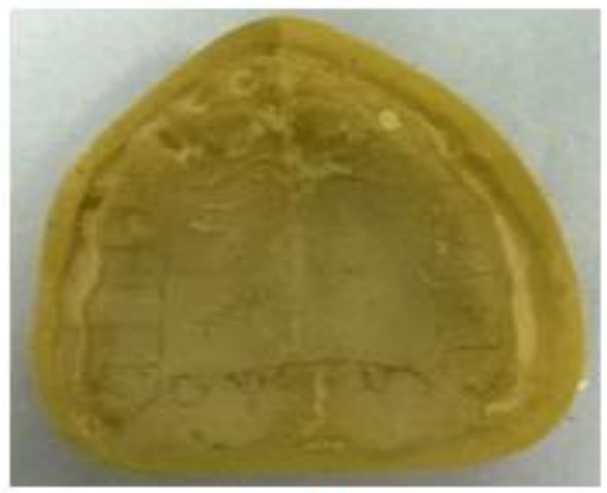

Fig 3 - Maxillary Master

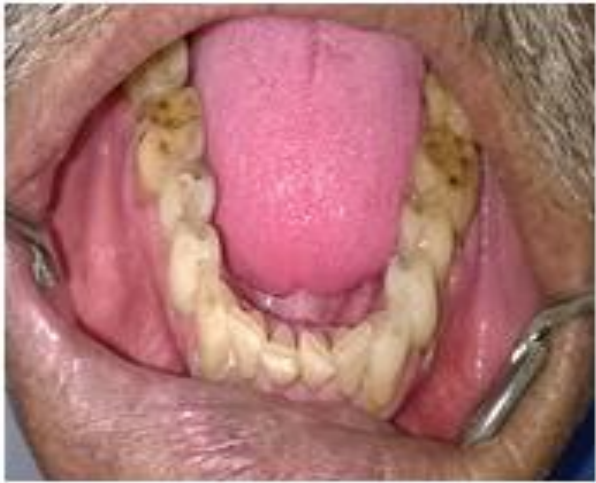

Fig 2 - Mandibular Arch

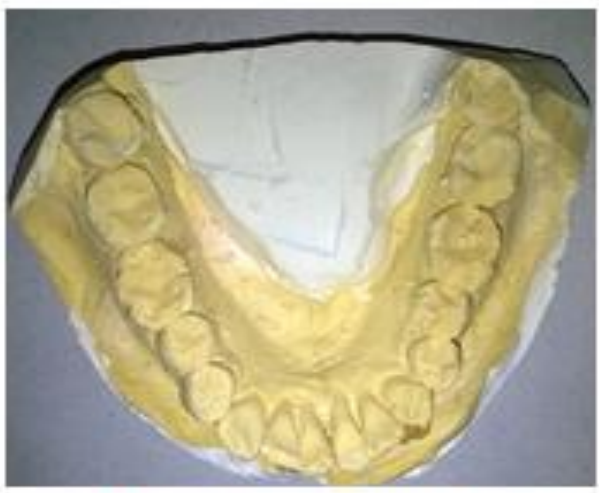

Fig 4 - Mandibular Master Cast 


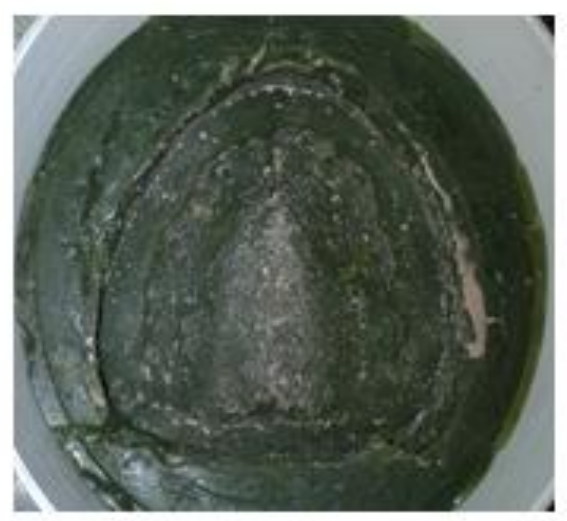

Fig 5 - Agar (Duplicating

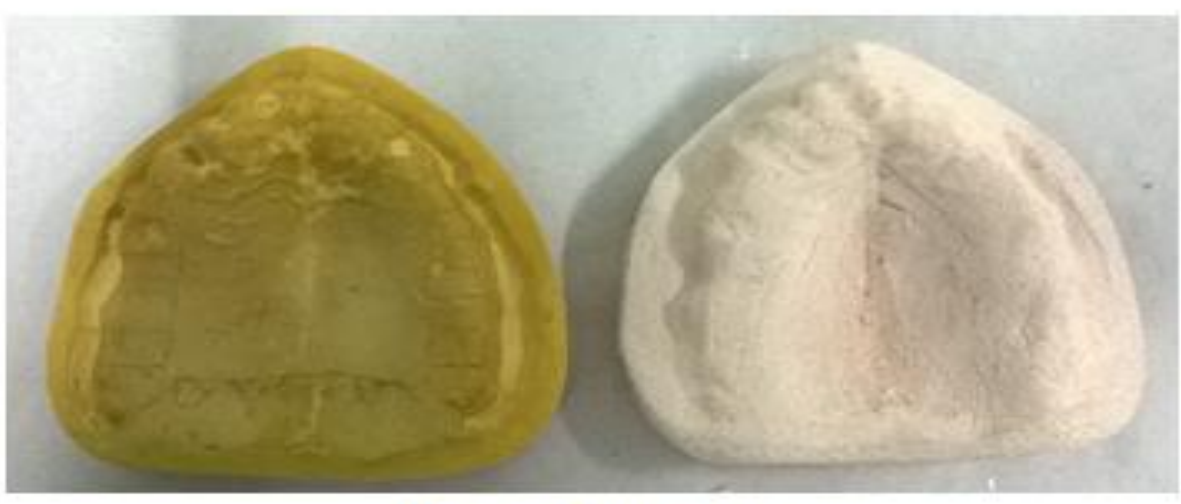

Fig 6 - Duplicated Master Cast
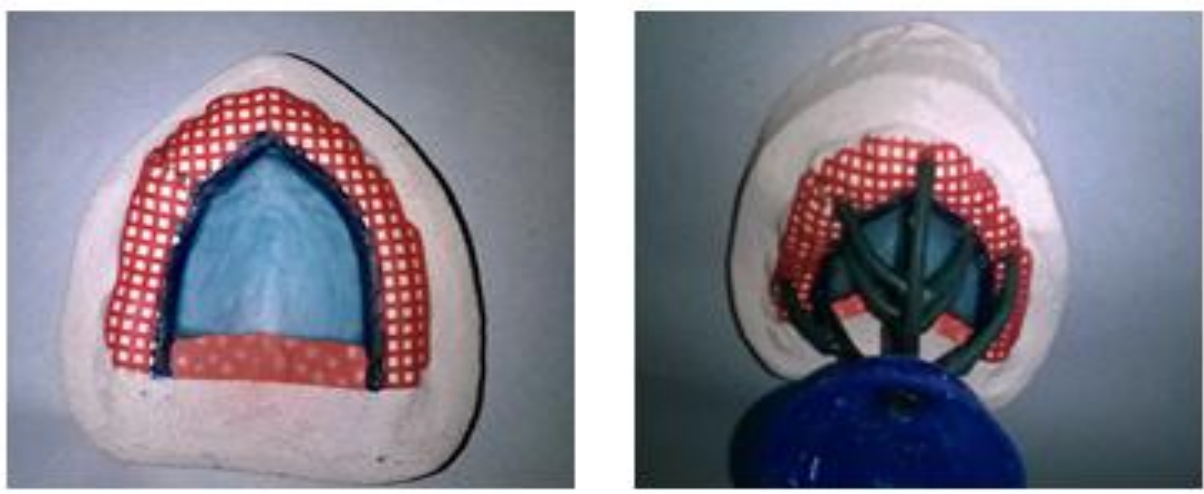

Fig 7 - Wax Pattern 


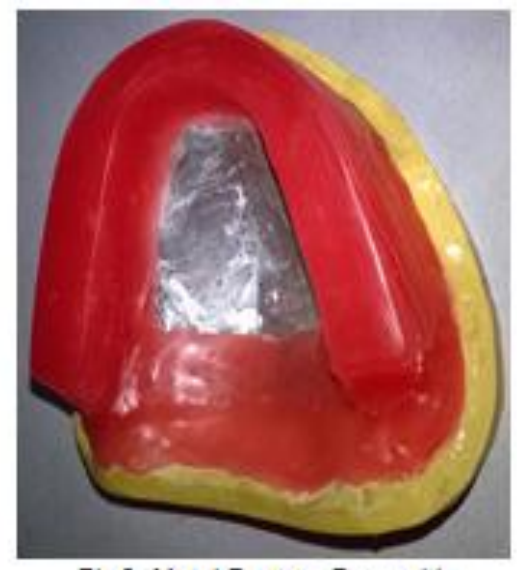

Fig 8 -Metal Denture Base with Qcclusa] Rim

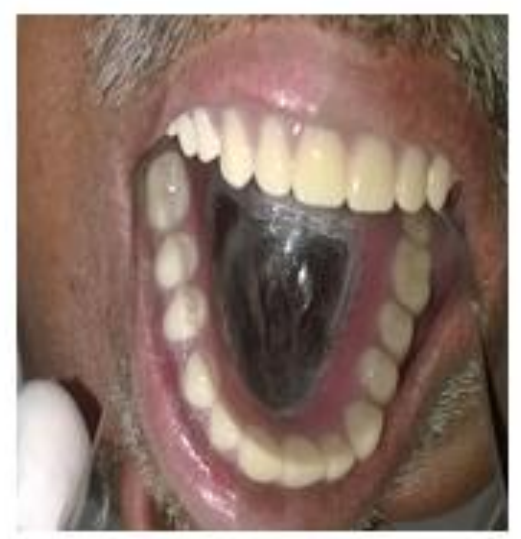

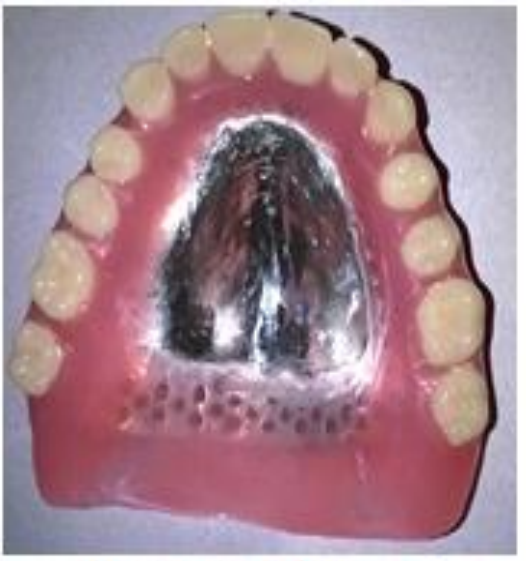

Fig 9 - Processed Maxillary

Denture

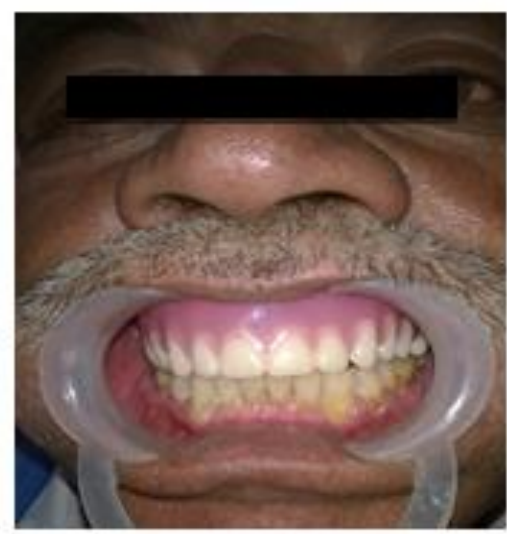

Fig 10 - Denture Insertion

\section{References:-}

1. Belfiglio EJ.Using metal bases in making complete dentures.J Prosthet Dent. 1987 Sep;58(3):314-7.

2. Driscoll CF, Masri RM. Single maxillary complete denture. Dent Clin North Am. 2004 Jul;48(3):567-83.

3. Ellinger CW, Rayson JH, Henderson D. Single complete denture. J Prosthet Dent. 1971 Jul;26(1):4-10.

4. Koper A. The maxillary complete denture opposing natural teeth: problems and somesolutions. J Prosthet Dent 1987;57(6):704-7

5. Mattie PA, Phoenix RD. A precise design and fabrication method for metal base maxillary complete dentures. $\mathbf{J}$ Prosthet Dent. 1996 Nov;76(5):496-9.

6. Zarb GA, Bolender CL, Hickey JC, Carlsson GE. Boucher's prosthetic treatment for edentulous patients. 11th ed St. Louis: CV Mosby, 1990:503. 